\title{
Additive Manufacturing of Custom Orthoses and Prostheses - A Review
}

\author{
Roland K. Chen ${ }^{\mathrm{a}}$ \\ krchen@umich.edu \\ Yu-an Jin ${ }^{\mathrm{a}}$ \\ jinyuan@umich.edu \\ Jeffrey Wensman ${ }^{\mathrm{b}}$ \\ jwensman@med.umich.edu \\ Albert Shih ${ }^{\mathrm{a}, \mathrm{c}}$ \\ shiha@umich.edu \\ ${ }^{a}$ Mechanical Engineering, University of Michigan, 2350 Hayward St., Ann Arbor, MI \\ 48109, USA \\ ${ }^{\mathrm{b}}$ University of Michigan Orthotics and Prosthetics Center \\ ${ }^{c}$ Biomedical Engineering, University of Michigan
}

Corresponding Author:

Albert J Shih

3001E EECS, 2350 Hayward St.

University of Michigan

Ann Arbor, MI 48109-2125

Phone: +1-734-647-1766

Fax: +1-734-936-0363

e-mail:shiha@umich.edu 


\section{Abstract}

This study reviews the progress of using additive manufacturing (AM) for custom orthoses and prostheses (O\&P) in the past 25 years. Foot orthoses (FOs), ankle-foot orthoses (AFOs), and prosthetic sockets are the most common types of O\&P that are custom fabricated. A brief introduction to traditional plaster molding fabrication techniques for custom O\&P are given for FO, AFO, and prosthetic sockets, followed by the AM process. Prior studies on AM of FOs, AFOs, and prosthetics sockets are reviewed. Applications of AM for other types of O\&P are also presented. Lastly, future trends and challenges for adoption of AM for fabrication of O\&P in clinical settings are discussed. 


\section{Introduction}

Orthoses and prostheses (O\&P) are assistive devices that help people with disabilities. Orthoses, colloquially known as braces, support and modify the structural and functional characteristics of human neuromuscular and musculoskeletal systems. For patients with impairments that contribute to functional limitations, orthoses are used to apply forces on the body for biomechanical needs. Prostheses are devices that replace missing body parts, such as a hand prosthesis. The portion remaining of the limb is referred to as the residual limb. The prosthetic socket is a cup-like structure that fits around the residual limb of amputees and transfers mechanical loading from the amputee to the prosthesis. The socket is critical for the comfort and function of prosthesis users.

O\&P are named according to the joint and the limb involved. The nomenclature for most common O\&P is listed in Table 1 [1]. Examples of foot orthoses (FO) and ankle-foot orthoses (AFO) are illustrated in Fig. 1. There is a growing need for O\&P due to an aging population, veterans injured in recent conflicts, and auto accidents. In 2013, Medicare approved payment for nearly 2.4 million orthotic codes, 2.07 million prosthetic services, and 5.9 million pedorthic codes that accounted for more than $\$ 734$ million, \$664 million, and \$255 million, respectively, in Medicare expenditures [2].

O\&P can be either custom fabricated or prefabricated. Prefabricated O\&P are less expensive and are readily available as off-the shelf products. However, custom O\&P have better fit to the patient's body and perform better than the prefabricated O\&P. A study of the prosthetic care of 581 veterans and service members with major traumatic limb loss from the Vietnam and Iraq war era [3] as well as in a study of long-term prosthesis use of patients with lower-limb amputation [4] have both reported that the fitness of O\&P is the most important factor for O\&P users' satisfaction. Traditionally, custom O\&P are manufactured using a labor intensive plaster molding technique. Additive manufacturing (AM) is an ideal technology for mass customization and provides the opportunity to eliminate much of this labor. The potential for AM has been demonstrated for rapid and cost-effective fabrication and transformative service of the custom O\&P. 
Table 1. Orthotic and prosthetic nomenclature [1]

\begin{tabular}{|c|c|c|c|}
\hline \multicolumn{4}{|c|}{ Upper Limb Orthoses } \\
\hline $\mathrm{HO}$ & Hand orthoses & WHO & Wrist-hand orthoses \\
\hline WO & Wrist orthoses & EWHO & Elbow-wrist-hand orthoses \\
\hline EO & Elbow orthoses & & \\
\hline \multicolumn{4}{|c|}{ Spinal Orthoses } \\
\hline CTLSO & \multicolumn{3}{|c|}{ Cervical-thoracic-lumbosacral orthoses } \\
\hline $\mathrm{CO}$ & Cervical orthoses & TLSO & Thoracic-lumbosacral orthoses \\
\hline TO & Thoracic orthoses & LSO & Lumbosacral orthoses \\
\hline LO & Lumbar orthoses & $\mathrm{SIO}$ & Sacroiliac orthoses \\
\hline \multicolumn{4}{|c|}{ Lower-Limb Orthoses } \\
\hline FO & Foot orthoses & AFO & Ankle-foot orthoses \\
\hline KO & Knee orthoses & KAFO & Knee-ankle-foot orthoses \\
\hline $\mathrm{HpO}$ & Hip orthoses & HKAFO & Hip-knee-ankle-foot orthoses \\
\hline \multicolumn{4}{|c|}{ Prostheses } \\
\hline $\mathrm{AE}$ & Above elbow & $\mathrm{BE}$ & Below elbow \\
\hline AK & Above knee & BK & Below knee \\
\hline
\end{tabular}

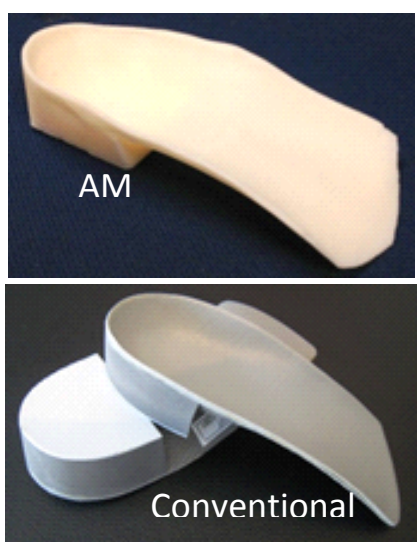

(a)
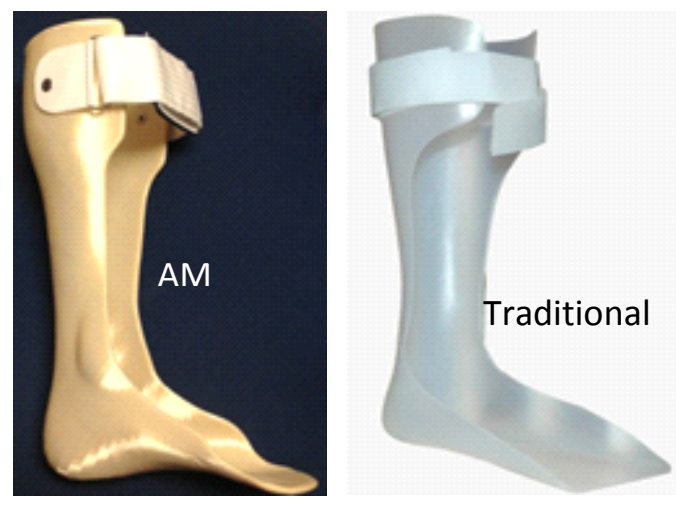

(b)

Fig. 1. Examples of orthosis and prosthesis fabricated using the traditional and additive manufacturing: (a) foot orthosis and (b) ankle-foot orthosis

Figs. 2(a) and (b) show the quantity and Medicare expenditures of the most common types of O\&P reported by the Centers for Medicare \& Medicaid Services [5]. FO is the largest in terms of quantity (66.0\%) and expenditures (20.9\%). AFO has only $4.3 \%$ in quantity but costs $10.4 \%$ in overall expenditure. Similarly, AK and BK have 1.3\% in quantity but cover $10.3 \%$ in overall expenditure. The percentages of LSO and KO in overall expenditure are $20.8 \%$ and $12.6 \%$, 
respectively, but most of these two types of orthoses are prefabricated and fitted to the patients. In this paper, we focus on reviewing AM research on FO, AFO, and lower limb prosthetic sockets (AK and BK). In the next three sections, we first provide an introduction to the traditional manufacturing process for custom O\&P and then review the AM research for FO, AFO, and lower limb prosthetic sockets, respectively. AM of other types of O\&P are discussed in the following section. Lastly, future trends and challenges are summarized.

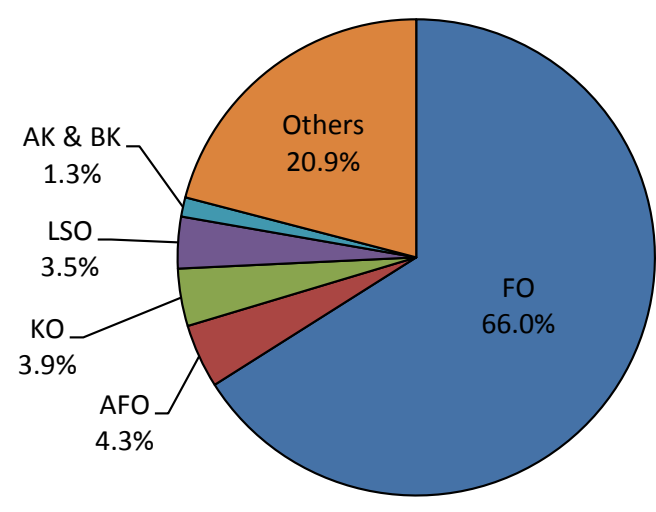

(a)

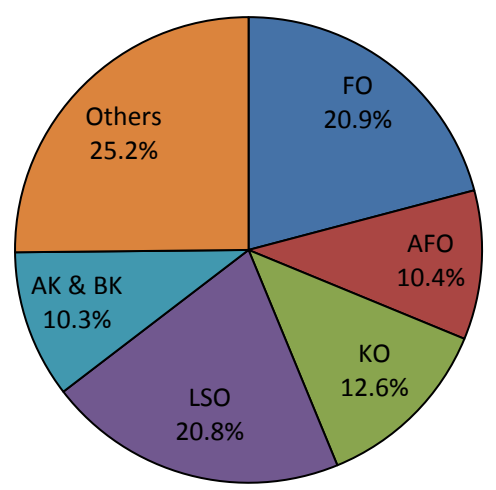

(b)

Fig. 2. O\&P usage data from Centers for Medicare \& Medicaid Services: (a) quantity and (b) expenditures.

\section{Traditional and Additive Manufacturing of the Foot Orthosis}

FOs are used to support and align the foot to prevent or correct foot deformities, provide an even distribution of the body weight, or to improve the functions of the foot. Depending on the range of movement in the joints allowed or activity levels, orthotists (or pedorthists) can prescribe three types of FO: rigid, semi-rigid, and soft.

For soft FOs made of soft foam material, Fig. 3 shows three key devices for fabrication. One is the pin-based contact digitizer machine (Fig. 3(a)) that measures the plantar surface profile of the foot. Depth of the pins in contact with the foot is measured and converted by the O\&P computer-aided design (CAD) software (Fig. 3(b)) to the profile of the insole. This profile, after modification by the orthotist, is used in a 3-axis computer numerical control (CNC) carving machine (Fig. 3(c)) to fabricate the FO made of ethylene-vinyl acetate (EVA) material with about 35 Shore A hardness. Machining time of a standard size FO in the CNC carver (by Amfit ${ }^{\circledR}$ ) takes 30 to $60 \mathrm{~min}$. 


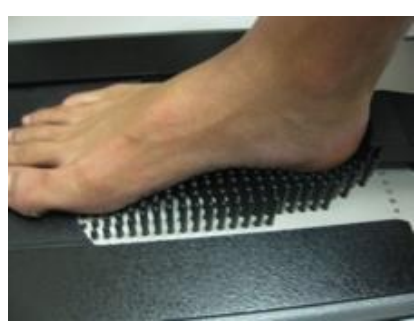

(a)

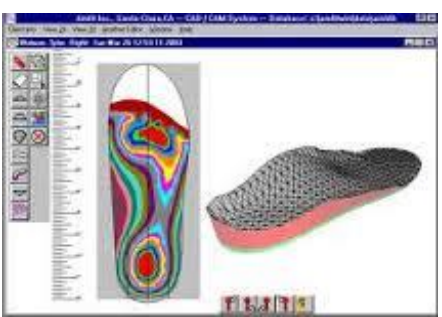

(b)

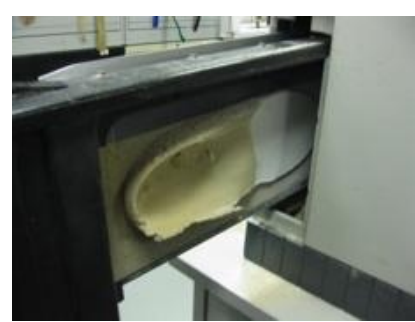

(c)

Fig. 3 Manufacturing of soft FOs: (a) foot plantar surface profile measurement device based on elevating contact pins, (b) O\&P CAD software, and (c) CNC carving machine for 3-axis milling of FO (by Amfit ${ }^{\circledR}$ ).

For rigid and semi-rigid FOs, the traditional plaster molding and vacuum forming processes are used for fabrication. As shown in Fig. 4(a), the patient's foot is pressed into a foam box to create a negative impression of the plantar surface. This negative impression is used as a mold for plaster to create the positive model of the foot (Fig. 4(b)). The positive model is placed on a vacuum table and then draped with a pre-heated thermoplastic sheet (Fig. 4(c)). Vacuum is applied to mold the thermoplastic sheet into the plaster mold. A heel block is added (Fig. 4(d)). The extra material around the edges is trimmed and smoothed to finish the FO, as shown in Fig. $1(a)$.
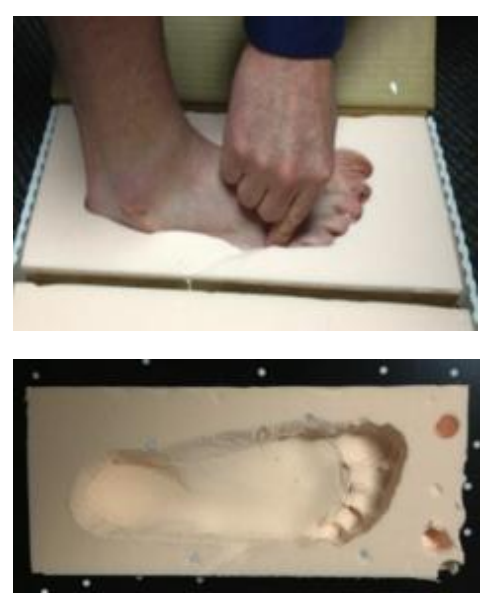

(a)

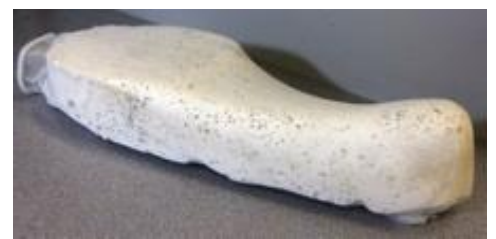

(b)

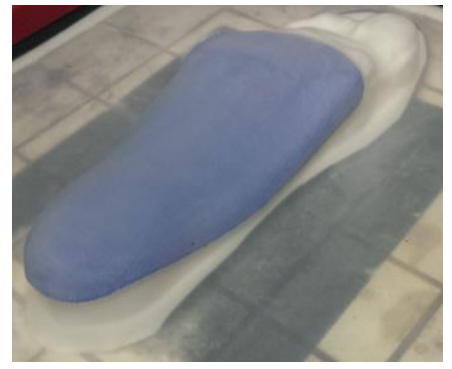

(c)

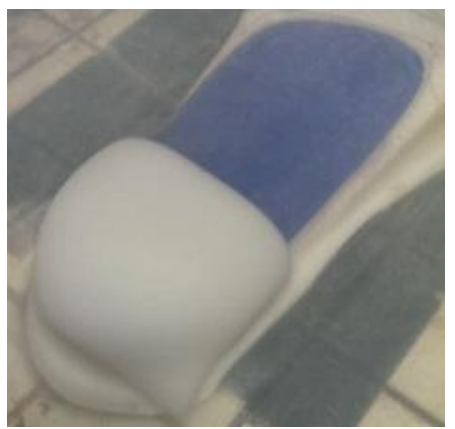

(d)

Fig. 4 Fabrication of rigid and semi-rigid FOs: (a) foam impression box, (b) plaster mold made from the foam box, (c) vacuum forming of the thermoplastic sheet over the mold, and (d) adding the heel block after the vacuum forming. 


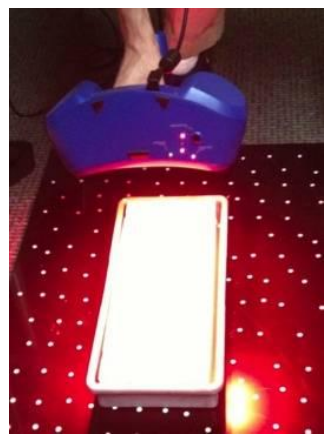

(a)

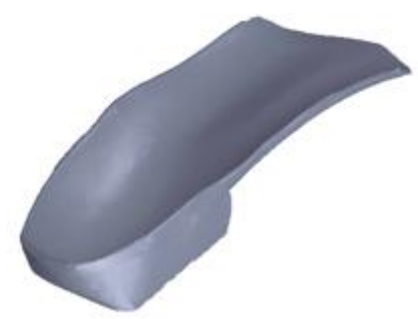

(d)

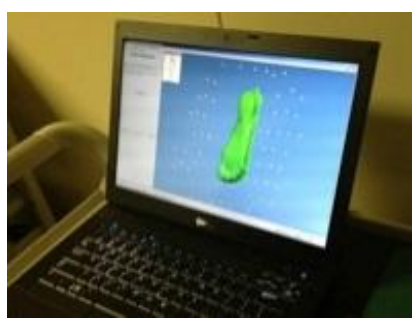

(b)

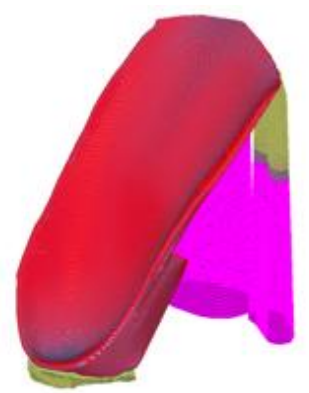

(e)

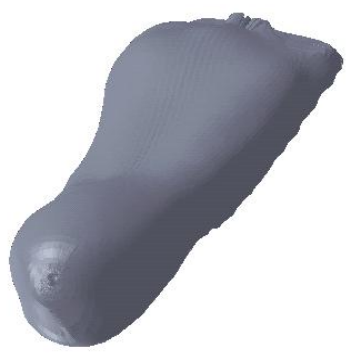

(c)

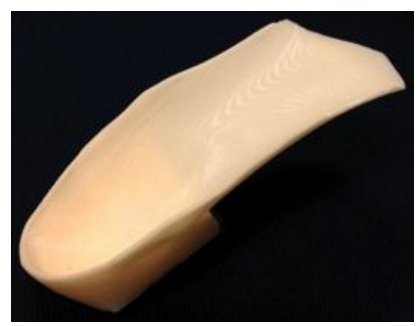

(f)

Fig. 5 Procedure of AM for FO: (a) 3D scanning of the foam box, (b) geometry modification in O\&P Tracer® CAD, (c) modified STL file of a positive foot model, (d) merged FO (insole and heel), (e) FO setup for AM, and (f) FO made by FDM.

Figure 5 shows the steps of fabricating the FO using AM. First, a 3D scanner captures the 3D geometry by either scanning the impression of the foam box (Fig. 5(a)) or by directly scanning the patient's foot. Orthotists use an O\&P CAD software (e.g. Tracer ${ }^{\circledR}$ CAD by Ohio Willow Wood) to modify the geometry, as shown in Fig. 5(b). The modified geometry (Fig. 5(c)) is exported as a stereolithography (STL) file and transferred to another software (e.g. Magics ${ }^{\mathrm{TM}}$ by Materialise) with the "offset" function to generate a given thickness of a surface representation to make a solid model. A heal block is generated and exported as another STL file. These two STL files are merged, and a single STL file of the solid representation of the FO is created (Fig. 5(d)). This solid representation of the FO can be used for AM, as shown in Fig. 5(e) for the tool path planning based on the fused deposition modeling (FDM) method. A FO fabricated by FDM is illustrated in Fig. 5(f).

The design and manufacture of custom orthoses and prostheses consist of three main steps: geometry capture, device design, and device manufacture. For a given device manufacturing 
method (either traditional or AM), there is a range of geometry capturing methods, including the foam box (Fig. 4(b)), pin-based contact digitizer (Fig. 3(a)), plaster molding (Fig. 4(b)), optical scanning (Fig. 5(a)), computed tomography and magnetic resonance imaging (Fig. 14(a)). Except foam box and contact digitizer are more exclusively used for measuring foot profile, all other methods can be applied to capture geometry of most types of orthoses and prostheses. A combination of multiple methods can also be used to achieve a better result. Each geometry capturing method could be utilized for either the traditional or AM.

Table 2 chronologically summarizes the AM process, equipment, and material used in prior studies for AM of FO. In 2008, Pallari et al. [6] proposed a framework for mass customization of FOs for rheumatoid arthritis and showed that additive manufactured FOs can effectively redistribute the pressure over the arch and heel. Saleh and Dalgarno [7] performed a cost and benefit analysis comparing two AM processes, FDM and selective laser sintering (SLS), for FO. The estimated cost for additively manufactured one pair of FO is comparable to the cost using traditional plaster molding technique. Sun et al. [8] used a 3D-printing technique (PolyJet ${ }^{\circledR}$ ) for AM of shoe insoles for 50 healthy subjects and showed a $5 \%$ decrease in heel and forefoot pressure, and a $5 \%$ increase in pressure over the foot arch. In this study, all feet geometry was obtained using a 3D scanner in the non-weight bearing conditions. Cook et al. [9] utilized several AM processes to fabricate hard shells of custom FOs for clubfoot and a positive model of the soft inner layer. This positive model was used to fabricate a negative silicone mold to cast the polyurethane (PU) foam as the soft inner layer for the FO (Fig. 7(a)).

A subsequent study by Pallari et al. [10] compared standard custom FOs with FOs made by SLS (Fig. 6(a)). The gait parameters (velocity, cadence, cycle time of each leg) and perception of fit on seven rheumatoid arthritis patients were investigated. Results showed no significant differences. A question was raised about whether the foot geometry should be captured in the weight-bearing or non-weight-bearing condition. They also indicated that the cost of AM of FOs was comparable to traditional FOs. Another study by Pallari et al. [11] proposed integrating sensors in FO and the use of different conforming surfaces. In this study, Pallari indicated that in order to achieve mass production of custom FOs by AM, a software platform tailored for AM of custom orthoses would be needed.

Salles and Gyi [12,13] studied the AM of custom insoles on recreational runners, and compared the performance of $\mathrm{AM}$ and regular insoles. Although there was no significant difference in comfort, insoles made using AM showed a more evenly distributed pressure over the entire foot. The weight bearing conditions when capturing foot geometry was also a concern. AM offered a limited selection of materials, which were too rigid for the insoles. In a prolonged 
and controlled study (3 months of trial) by Salles and Gyi [14], the group wearing custom insoles fabricated by AM (Fig. 7(b)) showed significantly less discomfort in the heel, better overall fit, less dorsiflexion at footstrike, and lower ankle eversion and peak pressure under the heel which indicated reduced risk for injury. Saleh performed a thorough study on cost of fabricating FOs with different AM techniques, including FDM, SLS, stereolithography (SLA), and inkjet 3D printing, against the traditional soft FO (made by CNC carving shown in Fig. 3). SLS showed the highest productivity and lowest cost per pair of FO. However, the cost is still considerably higher than that of traditional soft FOs [15]. Dombroski et al. [16] studied the 3D scanning and FDM of a low-cost custom FO and validated the feasibility and effectiveness in one user.

Telfer et al. [17] developed a FO with adjustable elements to relieve pressure at the metatarsal heads (Fig. 7(c)) and found that it could significantly reduce the pressure under the targeted metatarsal heads. Their results demonstrated the capability of AM to fabricate FOs with complex design and better functionality. Chen et al. [18] demonstrated that using sparse structure in the $\mathrm{FO}$ design can reduce the AM time and cost.

AM has become a cost-effective way to fabricate custom FOs. Companies, such as SOLS ${ }^{\circledR}$, podfo $^{\circledR}$, and 3DOrthotics, have commercialized FOs fabricated using AM, as shown in Fig. 7(d).

Table 2 Summary of AM studies on foot orthosis

\begin{tabular}{|c|c|c|c|c|c|}
\hline Authors & Year & AM Process & Printer & Material & Ref \\
\hline Pallari et al. & 2008 & SLS & 3D Systems Vanguard SLS & $\begin{array}{l}\text { Nylon } 12 \\
\text { (DuraForm }{ }^{\circledR} \text { PA) }\end{array}$ & [6] \\
\hline Saleh and Dalgarno & 2009 & FDM and SLS & $\begin{array}{l}\text { Dimension NST } 768 \text { FDM } \\
\text { System } \\
\text { 3D Systems Vanguard SLS }\end{array}$ & $\begin{array}{l}\text { ABS }(P 400) \\
\text { Nylon } 12 \\
\left.\text { (DuraForm }{ }^{\circledR} \mathrm{PA}\right)\end{array}$ & [7] \\
\hline Sun et al. & 2009 & PolyJet & Object & $\mathrm{N} / \mathrm{A}$ & [8] \\
\hline Cook et al. & 2010 & SLS & 3D Systems & $\begin{array}{l}\text { Nylon } 12 \\
\text { (DuraForm }{ }^{\circledR} \text { PA) }\end{array}$ & [9] \\
\hline Pallari et al. & 2010 & SLS & 3D Systems Vanguard SLS & $\begin{array}{l}\text { Nylon } 12 \\
\text { (DuraForm }{ }^{\circledR} \text { PA) }\end{array}$ & [10] \\
\hline Pallari et al. & 2010 & SLS & 3D Systems Vanguard SLS & $\mathrm{N} / \mathrm{A}$ & [11] \\
\hline Salles and Gyi & 2012 & SLS & $\mathrm{N} / \mathrm{A}$ & $\begin{array}{l}\text { Nylon } 12 \\
\left.\text { (DuraForm }{ }^{\circledR} \mathrm{PA}\right)\end{array}$ & [12] \\
\hline Salles and Gyi & 2012 & SLS & $\mathrm{N} / \mathrm{A}$ & $\begin{array}{l}\text { Nylon } 12 \\
\text { (DuraForm }{ }^{\circledR} \mathrm{PA} \text { ) }\end{array}$ & [13] \\
\hline Telfer et al. & 2012 & SLS & $\begin{array}{l}\text { EOSINT P } 700 \text { SLS (EOS } \\
\text { GmbH, Munich, Germany) }\end{array}$ & $\begin{array}{l}\text { PA2200 Nylon- } \\
12\end{array}$ & [17] \\
\hline Salles and Gyi & 2013 & SLS & 3D Systems & $\begin{array}{l}\text { Nylon } 12 \\
\text { (DuraForm }{ }^{\circledR} \mathrm{PA} \text { ) }\end{array}$ & [14] \\
\hline Saleh & 2013 & SLA/SLS/FDM & & & [15] \\
\hline Dombroski et al. & 2014 & FDM & $\begin{array}{l}\text { Makerbot }^{(\Theta)} \text { (Makerbot } \\
\text { Industries, Brooklyn, NY) }\end{array}$ & ABS & {$[16]$} \\
\hline Chen & 2014 & FDM & Fortus $400 \mathrm{mc}$ & ABS & [18] \\
\hline
\end{tabular}




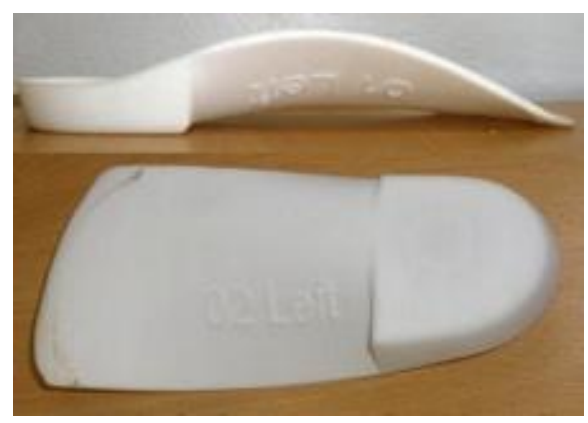

(a)

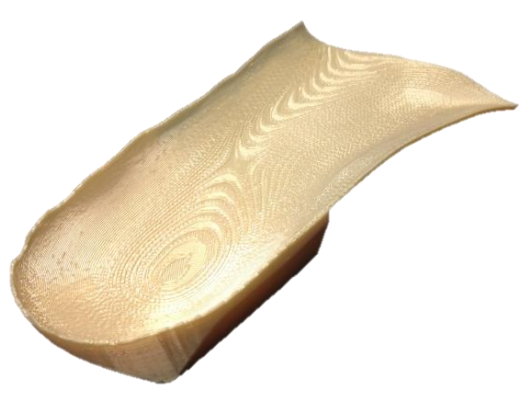

(b)

Fig. 6 FOs fabricated by: (a) SLS [10] and (b) FDM [18]

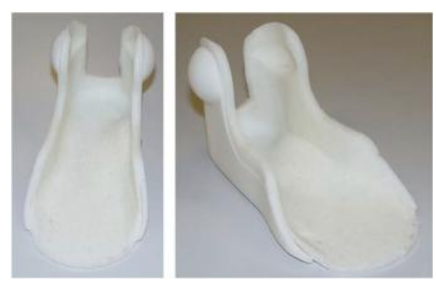

(a)

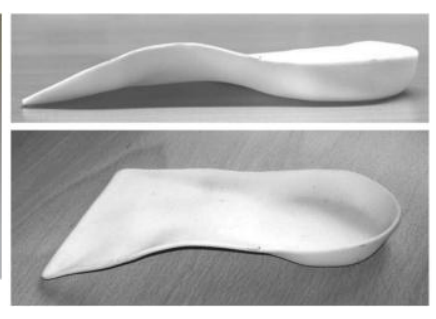

(b)

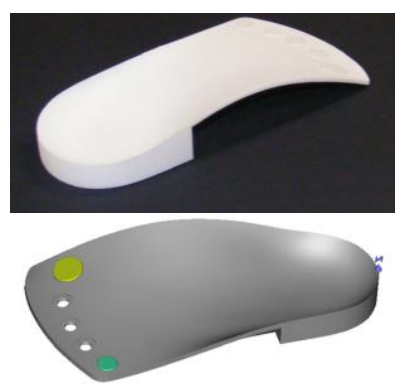

(c)

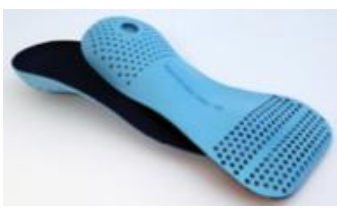

(d)

Fig. 7 AM of FOs: (a) for clubfoot correction [9], (b) for personalized insoles for runners [14], (c) with adjustable elements to relieve pressure [17], and (d) for commercialization.

\section{Traditional and Additive Manufacturing of the Ankle-Foot Orthosis}

AFOs support and align the ankle and foot and are commonly used to treat the drop-foot syndrome after stroke, multiple sclerosis and cerebral palsy patients. AFOs suppress the spastic and overpowering muscles, assist weak and paralyzed muscles, prevent or correct deformities, and improve the functions of the ankle and foot.

The traditional plaster molding technique to fabricate a custom AFO is shown in Fig. 8(a). Step 1 is the measurement including the length, successive circumferences, and mediolateral and anteroposterior dimensions of the ankle and foot. In Step 2, a layer of tubular stockinet covers the foot, ankle, and leg to create a protective interface and maintains the shape of the soft tissue. Bony prominences or other important guiding landmarks are marked in this stockinet layer. A negative impression is taken with a plaster of Paris bandage or a fiberglass tape 
around the foot, ankle, and leg. While the plaster mold hardens, the clinician supports the ankle and foot in the desired position, sometimes applying a light corrective force. Upon hardening of the plaster or fiberglass mold, it is carefully cut or sectioned and removed, preserving the shape and alignment of the foot, ankle, and leg. In Step 3, a positive model is created by pouring a bucket of plaster slurry into the sealed negative plaster or fiberglass shell mold. A steel mandrel is embedded into the positive plaster model for holding in subsequent production steps. Although the positive plaster model is a 3D representation of the ankle and foot, its shape needs to be modified to open space around bony prominence areas or sites prone to pressure ulcers to reduce the contact pressure and enhance comfort. In Step 4, additional plaster is added to relieve pressure over ankle bone and removed from areas where higher pressures are expected to be applied during the AFO's use. The surface of the positive plaster model is smoothed by sanding. In Step 5, a polypropylene (PP), polyethylene (PE), PP-PE copolymer, or other thermoplastic sheet is heated in an oven to the plastic state, wrapped around the plaster model and formed to the model via vacuum. Once the plastic has cooled and returned to its solid state, trimlines are delineated on the formed plastic and the rough edges are smoothed. In Step 6 , the finished AFO is fitted to the patient and the patient's gait is observed for fit and function. The duration for traditional manufacturing of an AFO usually takes about one week. In a central fabrication setting with technicians working three shifts, the manufacturing time of an AFO can be shortened to one day.

For AM of AFO, as shown in Fig. 8(b), Step 1 is the 3D scanning of the ankle and foot of the patient. The plantar surface of the patient's foot is also scanned, either using the foam impression box (Fig. 5(a) for FO fabrication) or by direct scanning. In Step 2, the scan data is processed using a CAD software to stich two scans (one on ankle/foot and another on the foam impression box) by aligning reference dots placed on the edge of the foam box. These dots were scanned during both scans and used in the CAD software for alignment and stitching of two scans. The trimlines for AFO are created and smoothed manually using the CAD software. In Step 4, the path and support structure for AM of AFO are designed. The AFO is fabricated in Step 5. 


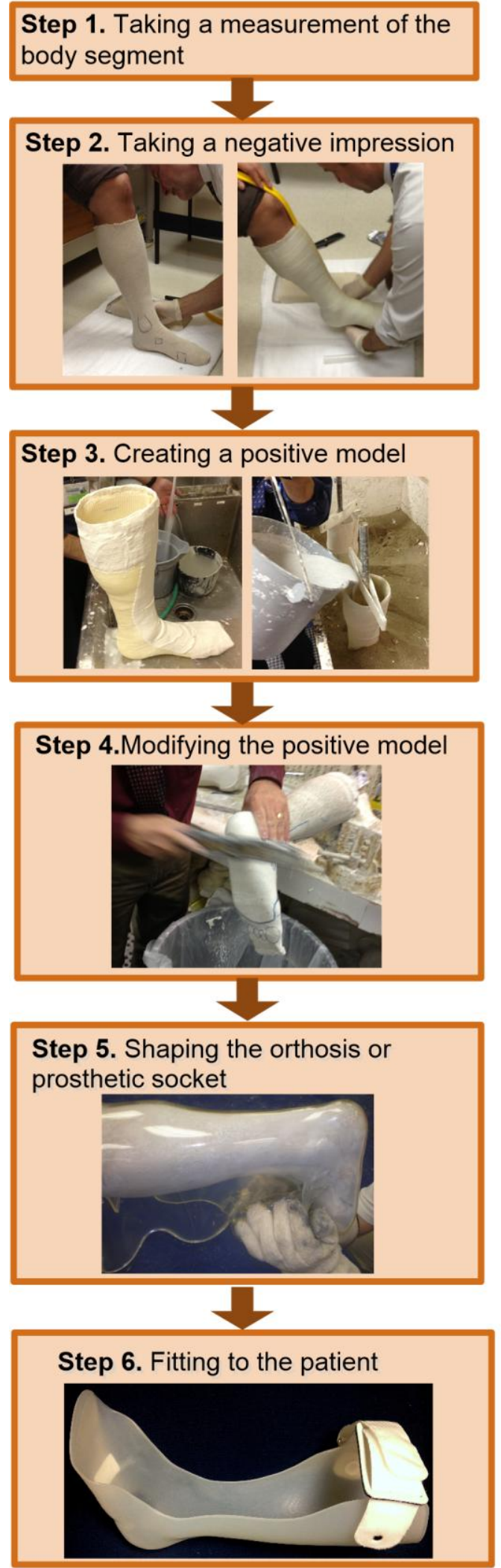

(a)

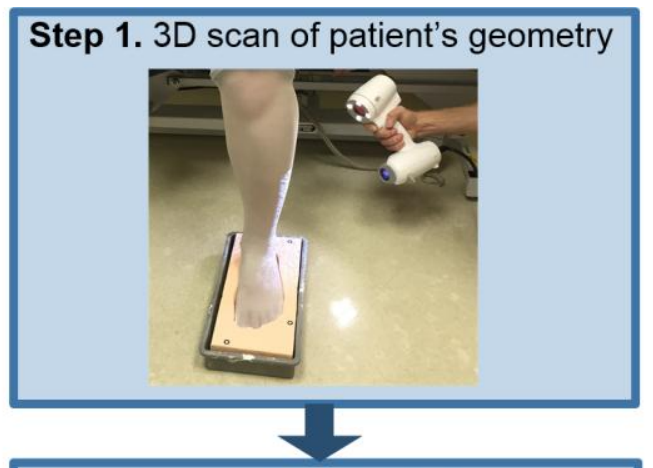

Step 2. Geometry modification

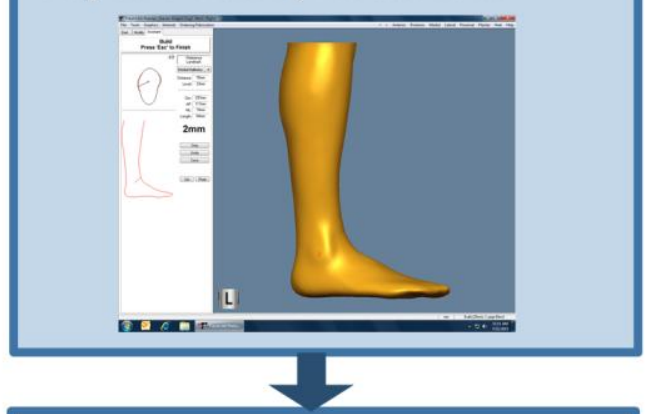

Step 3. Converting modified geometry to orthosis

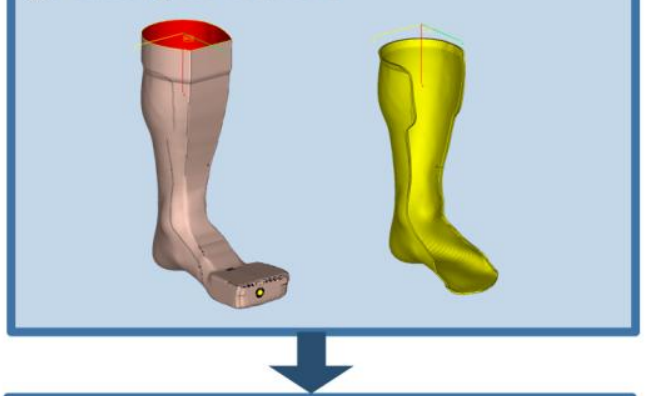

Step 4. Additive manufacturing of orthosis

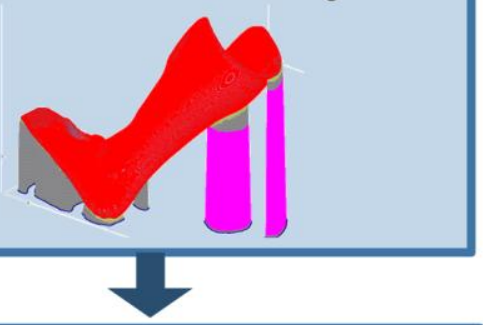

Step 6. Fitting to the patient

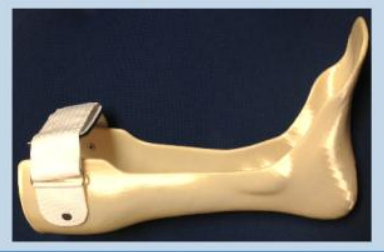

(b)

Fig. 8 Manufacturing processes for AFOs: (a) conventional and (b) AM. 
Table 3 chronologically summarizes studies on AM of AFOs from the technical and clinical perspectives. From the technical perspective, the concept of using AM for AFO was published by Milusheva et al. [19] in 2005. Milusheva et al. also proposed to use exchangeable elastic elements to adjust the mechanical properties of the AFO made by AM [20]. Faustini et al. [21] fabricated the passive dynamic AFOs (Fig. 9(a)) using SLS of Nylon 12, glass-fiber filled Nylon 12, and Nylon 11 materials. Compared to the carbon fiber AFO, results show AFOs made by SLS had adequate stiffness and better damping. Nylon 11 was the SLS material that could withstand the whole range of destructive testing. Pallari et al. [10] applied finite element modelling (FEM) and topology optimization to design AFOs fabricated by SLS. The concept of integrating sensors (e.g. temperature, pressure, and humidity) in 3D-printed AFO was proposed. Mavroidis et al. tested three AFOs, one fabricated by the conventional method (using PP) and the other two by SLA: one using the rigid Accura SI 40 material and the other using the flexible Somos ${ }^{\circledast} 9120$ UV material (Fig. 9(b)). The gait study on one subject showed equivalent walking speed and step length and doubled support time for AFOs made by SLA in comparison with conventional AFO [22].

Schrank and Stanhope [23] proposed a five-step customization and manufacturing framework on subject characterization, alignment of the foot and leg segment using landmarks, and orientation in SLS for dimensional accuracy. Results showed that SLS can produce an AFO with high accuracy (Fig. 9(c)). Telfer et al. [17] developed the AFO with adjustable stiffness for ankle joint in the sagittal plane (shown in Fig. 9(d)) and demonstrated the effect of stiffness on ankle kinematics in a healthy subject. Creylman et al. [24] tested conventional PP and SLS AFOs (shown in Fig. 9(e)) on eight subjects with unilateral drop foot gait, evaluated gait performance and concluded that SLS AFOs had at least equivalent performances as conventional AFOs. Schrank et al. [25] integrated the CAD model parameterization and FEM analysis to quantitatively tune, predict and experimentally validate the bending stiffness of AFOs made by FDM. AFOs with different stiffness levels were fabricated (Fig. 9(f)). Chen et al. [26] measured the strain on a conventional co-polymer (blend of PP and PE) AFO and two FDM AFOs with PC-ABS and ULTEM ${ }^{T M}$ materials (Fig. 9(g)). Results showed that FDM was capable of fabrication stiffer AFOs and had the potential for advanced light-weight designs. Harper et al. [27] conducted a clinical evaluation on 10 subjects with unilateral lower-limb impairments and measured the gait of subjects using regular carbon fiber and stiffness-matched SLS AFOs (Fig. $9(h))$. Minimal differences in gait performance were observed. 


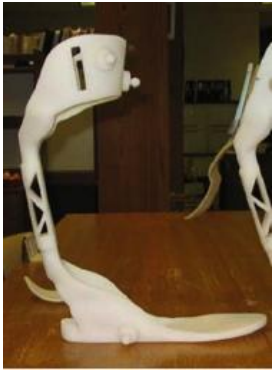

(a)

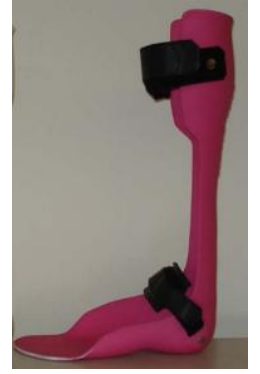

(e)

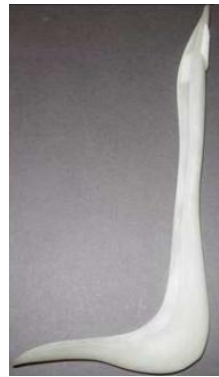

(b)

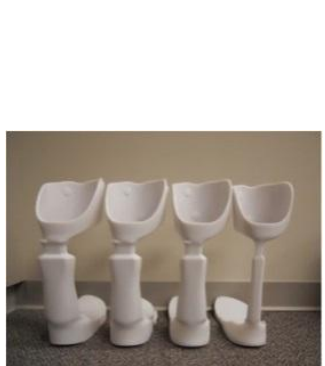

(f)

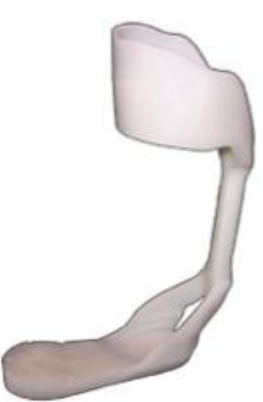

(c)

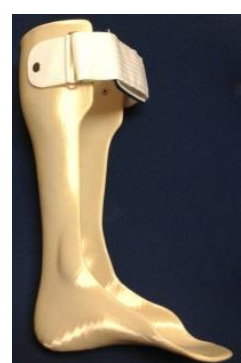

(g)

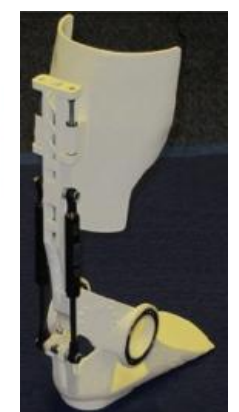

(d)

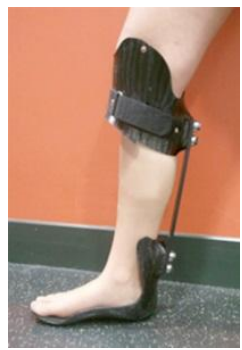

(h)

Fig. 9 Examples of AM AFOs, produced by: (a) Faustini et al. [21], (b) Mavroidis et al. [22], (c) Schrank et al. [23], (d) Telfer et al. [17], (e) Creylman et al. [24], (f) Schrank et al. [25], (g) Chen et al. [26], and (h) Harper et al. [27].

Table 3 Summary of studies on AM of ankle-foot orthoses

\begin{tabular}{|c|c|c|c|c|c|}
\hline Authors & Year & AM Process & Printer & Material & Ref \\
\hline Milusheva et al. & 2005 & $\mathrm{~N} / \mathrm{A}$ & N/A & $\mathrm{N} / \mathrm{A}$ & [19] \\
\hline Milusheva et al. & 2007 & SLS & $\mathrm{N} / \mathrm{A}$ & $\mathrm{N} / \mathrm{A}$ & [20] \\
\hline Faustini et al. & 2008 & SLS & Vanguard HS Sintersation & $\begin{array}{l}\left.\text { DuraForm }{ }^{\circledast}\right) \mathrm{PA} \\
\text { DuraForm }^{\circledR} \mathrm{GF} \text {, } \\
\text { Rilsan }^{\circledR} \mathrm{D} 80\end{array}$ & [21] \\
\hline Mavroidis et al. & 2011 & SLA & 3D Systems Viper Si2 SLA & $\begin{array}{l}\text { Accura SI40, } \\
\text { Somos } 9120 \text { UV }\end{array}$ & [22] \\
\hline $\begin{array}{l}\text { Schrank and } \\
\text { Stanhope }\end{array}$ & 2011 & SLS & Vanguard HS Sintersation & DuraForm $^{(B)} \mathrm{EX}$ & [23] \\
\hline Telfer et al. & 2012 & SLS & $\begin{array}{l}\text { EOSINT P700 SLS (EOS } \\
\text { GmbH, Munich, Germany) }\end{array}$ & $\begin{array}{l}\text { PA2200 Nylon- } \\
12\end{array}$ & [17] \\
\hline Creylman & 2013 & SLS & $\begin{array}{l}\text { P760 (EOS GmbH, Munich, } \\
\text { Germany) }\end{array}$ & $\begin{array}{l}\text { PA2201 Nylon- } \\
12\end{array}$ & [24] \\
\hline Schrank et al. & 2013 & FDM & Fortus $900 \mathrm{mc}$ & PC-ISO & [25] \\
\hline Chen et al. & 2014 & FDM & Fortus $900 \mathrm{mc}$ & $\begin{array}{l}\text { ULTEM, PC- } \\
\text { ABS }\end{array}$ & [26] \\
\hline Harper et al. & 2014 & SLS & Vanguard HS Sintersation & $\begin{array}{l}\text { Nylon } 11 \text { (PA } \\
\text { D80-ST) }\end{array}$ & [27] \\
\hline
\end{tabular}




\section{AM of Lower-Limb Prosthetic Sockets}

The traditional approach to the design and fabrication of a prosthetic socket starts with wrapping the residual limb in plaster and glass fiber bandages in order to capture its geometry in a cast. While wrapping the residual limb, the prosthetist palpates for potential pressure points at bony prominences and takes note of their locations. The cast of the residual limb is removed and filled with plaster slurry. Once the plaster is set, the plaster or fiberglass cast is destroyed, leaving a solid model (a positive mold) of the patient's residual limb. An alternative, and faster way to make the positive mold uses the 3D optical scanning of the residual limb. The scan data is converted into surface geometry and imported into a CNC milling machine to carve a model of the residual limb from a foam block. Whichever method is used to create the positive model, modifications are necessary to add volume to bony prominence and sensitive areas and remove volume from pressure tolerant (load bearing) areas. The location and thickness of build-ups to modify the positive plaster or foam mold are based on the evaluation and experience of the prosthetists, and could vary for each case. The positive socket mold is wrapped by a semimolten PE, PP, or co-polymer (blend of PE and PP) plastic sheet and vacuum-formed to conform to the shape of the mold. Alternatively, carbon fiber coated with epoxy resin can be wrapped around the positive mold and cured to form stronger, lighter-weight (yet more expensive) sockets for "active" amputees. Like FOs and AFOs, the current socket fabrication process is labor intensive. The process is also wasteful of material, as the plaster molds and excess fabrication materials are destroyed during fabrication. Should another socket be required due to the inevitable changes in the residual limb, the entire process has to be repeated.

The AM process, equipment, and material used to study AM of prosthetic socket are summarized chronologically in Table 4. Two research groups, one at the University of Texas (UT) at Austin and the other at Rehabilitation Institute of Chicago (RIC) / Northwestern University (NU) started studying AM of prosthetic socket in early 1990s [28-31]. The group at UT at Austin in collaboration with UT Health Science Center at San Antonio used SLS to fabricate prosthetic sockets [28, 29]. In 1991, the procedure of digitizing the residual limb using a 3D scanner, modifying the geometry using a CAD software, and using SLS to produce scaleddown sockets was presented [28]. Using AM, the fixture for the pylon can be integrated to the bottom of the socket [28]. A full sized socket was built in 1992 [29].

The group at RIC/NU applied the SLA [30] and FDM [31] to fabricate prosthetic sockets. Fig. 10(a) shows a wooden CNC carved socket, plaster residual limb model, and a SLA socket. In this study, a mechanical digitizer was used to obtain the 3D geometry of the plaster residual limb [30]. Fig. 10(b) shows the prosthetic socket made by FDM in the early 1990s [31]. 
Table 4 Summary of AM studies on prosthetic sockets

\begin{tabular}{|c|c|c|c|c|c|}
\hline Authors & Year & $\begin{array}{l}\text { AM } \\
\text { Process }\end{array}$ & Printer & Material & Ref \\
\hline Rogers et al. & 1991 & SLS & N/A & Polycarbonate & [28] \\
\hline Rogers et al. & 1992 & SLS & $\mathrm{N} / \mathrm{A}$ & Polycarbonate & [29] \\
\hline Rovick et al. & 1992 & SLA & $\mathrm{N} / \mathrm{A}$ & Acrylic & [30] \\
\hline Rovick & 1992 & FDM & Custom system & Polypropylene & [31] \\
\hline $\begin{array}{l}\text { Freeman and } \\
\text { Wontorcik }\end{array}$ & 1998 & SLA & SLA-250/40, 3D Systems & $\begin{array}{l}\text { Ciba-Geigy 5170, } \\
\text { DuPont Somos } \\
6110\end{array}$ & [32] \\
\hline Rogers et al. & 2000 & SLS & SinterStataion 2000 & Duraform & [33] \\
\hline Stephens et al. & 2000 & SLS & DTS SinterStation2500 plus $^{\mathrm{IM}}$ & Duraform & [34] \\
\hline Rogers et al. & 2001 & SLS & DTS SinterStation2500 plus ${ }^{\text {TM }}$ & Duraform & [35] \\
\hline Goh et al. & 2002 & FDM & Custom system & Polypropylene & [36] \\
\hline $\mathrm{Ng}$ et al. & 2002 & FDM & Custom system & PolyPropylene & [37] \\
\hline Tay el al. & 2002 & FDM & FDM 1600, Stratasys & Nylon P301 & [38] \\
\hline Faustini & 2005 & SLS & $\begin{array}{l}\text { Vanaguard SinterStation, 3D } \\
\text { Systems }\end{array}$ & $\begin{array}{l}\text { Duraform }{ }^{\mathrm{M}} \\
\text { Polyamide (Nylon } \\
12 \text { ) }\end{array}$ & [39] \\
\hline Fuh et al. & 2005 & FDM & Custom system, same as [37] & Polypropylene & [40] \\
\hline Herbert et al. & 2005 & 3D Printing & Z Corporation Z402-3 & $\begin{array}{l}\text { Plaster infiltrated } \\
\text { with PU }\end{array}$ & [41] \\
\hline Faustini et al. & 2006 & SLS & $\begin{array}{l}\text { Sinterstation } 3500 \text { by 3D } \\
\text { Systems }\end{array}$ & Duraform PA & [42] \\
\hline Rogers et al. & 2007 & SLS & DTS SinterStation2500 plus ${ }^{\mathrm{TM}}$ & $\begin{array}{l}\text { Nylon } 11 \text { and } \\
\text { Nylon } 12 \\
\text { (Duraform) }\end{array}$ & [43] \\
\hline Rogers et al. & 2008 & SLS & $\begin{array}{l}\text { Vanaguard SinterStation, 3D } \\
\text { Systems }\end{array}$ & $\begin{array}{l}\text { Nylon } 11 \text { (Rilsan } \\
\text { D80) }\end{array}$ & [44] \\
\hline Hsu et al. & 2008 & FDM & N/A & Polycarbonate & [45] \\
\hline Hsu et al. & 2010 & FDM & N/A & $\begin{array}{l}\text { Polycarbonate } \\
\text { coated with } \\
\text { unsaturated } \\
\text { polyester resin }\end{array}$ & [46] \\
\hline Montgomery & 2010 & SLS & $\begin{array}{l}\text { Vanaguard SinterStation, 3D } \\
\text { Systems }\end{array}$ & $\begin{array}{l}\text { Nylon } 11 \text { and } \\
\text { Nylon } 12\end{array}$ & [47] \\
\hline Chuang et al. & 2011 & FDM & $\mathrm{N} / \mathrm{A}$ & $\begin{array}{l}\text { Paper coated with } \\
\text { unsaturated } \\
\text { polyester resin }\end{array}$ & [48] \\
\hline Sengeh et al. & 2013 & 3D Printing & Objet500 Connex ${ }^{\mathrm{TM}}$ & $\begin{array}{l}\text { VeroWhitePlus }^{\mathrm{TM}} \\
\text { and } \\
\text { TangoBlackPlus }{ }^{\mathrm{TM}}\end{array}$ & [49] \\
\hline Doubrovski et al. & 2014 & 3D Printing & Objet500 Connex ${ }^{\mathrm{TM}}$ & $\begin{array}{l}\text { TangoBlackPlus } \\
\text { (FLX980) }^{\mathrm{TM}} \\
\text { VeroClear }^{\mathrm{TM}} \\
\text { (RGB810) }\end{array}$ & {$[50]$} \\
\hline
\end{tabular}




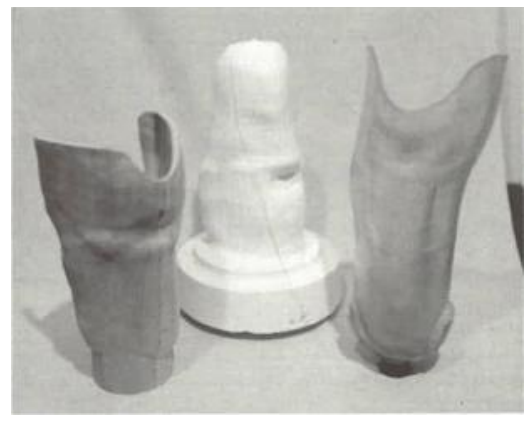

(a)

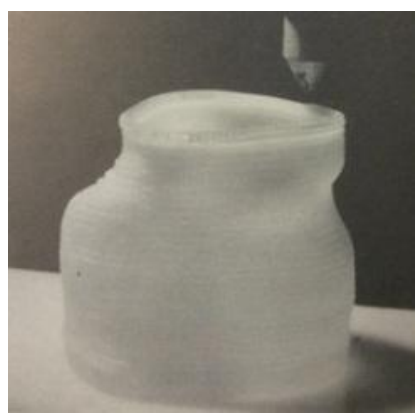

(b)

Fig. 10 Early studies on AM of prosthetic sockets: (a) a wooden CNC machined socket, a plaster mold and a SLA sockets (from left to right) [30] and (b) a prosthetic socket by FDM [31].

Freeman and Wontorick [32] investigated the cost and benefits of using two SLA materials to fabricate sockets. These two SLA sockets provided similar fit and comfort as compared to conventional sockets. SLA sockets were strong enough to support the weight of the subject during the fitting process. The research found SLA materials were brittle and might not be suitable to sustain the impacts and stresses in a socket [32]. AM provided benefits such as eliminating the manual process of making a positive mold and flexibility in shape complexity with a varied wall thickness. Improved material properties and lower cost were required for AM to fabricate sockets for clinical use.

The group at UT continued to use SLS with the nylon material (Duraform) for sockets [3335, 39, 42-44, 47]. Fig. 11 shows the evolution of AM sockets by the group at UT. Rogers et al. [33] and Stephens et al. [34] used a double-wall design for transtibial (below knee) prosthetic socket and evaluated on human subjects. The socket had a rigid outer shell ( $3 \mathrm{~mm}$ thick) and an inner variably compliant shell that allowed a $2 \mathrm{~mm}$ deflection at the peak pressure during gait. The comparison to a regular socket showed that the SLS socket had better comfort and similar gait performance [33]. Rogers et al. [35] conducted another study with four subjects testing SLS sockets. The survey results showed that a clinically acceptable fit in all subjects and a better comfort level, which resulted in increased prosthesis wearing time, could be achieved by the SLS prosthetic socket. Gait results showed no significant differences when compared to conventional sockets. However, one of the four sockets fractured and broke when the subject stepped off a bus. This suggested a need for better quality control and need of further study of the build parameters [35].

In 2005, the UT group advanced the design of prosthetic sockets by incorporating compliant features using topology optimization to relieve contact pressure [39]. In this study, 
pressure transducers were integrated in the spiral compliant areas. In comparison to noncompliant sockets, the compliant socket reduced the average pressure by $20 \%$ and the peak pressure by $23-45 \%$ [39]. A follow-up study on the socket with variably compliant design had the subject acclimate to all the sockets at the time of testing and showed significant reduction in contact pressure [44]. An experimental and theoretical framework for AM of prosthetic sockets by incorporating FEM to ensure structural reliability was presented [42]. Validated by experimental results, the predicted failure strength of the socket was within $3 \%$ of the experimental measurements. A summary of prior studies of AM of prosthetic sockets before 2007 was provided by Rogers et al. [43]. In 2010, the concept of an actively actuated prosthetic socket with inflatable/deflatable elements to account for volumetric changes of the residual limb was proposed [47]. The achievable deflection of both flat and curved membrane specimens were fabricated using SLS and tested to show the feasibility.

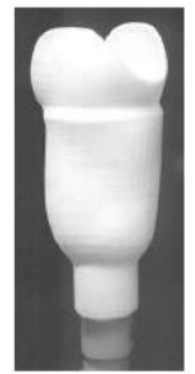

(a)

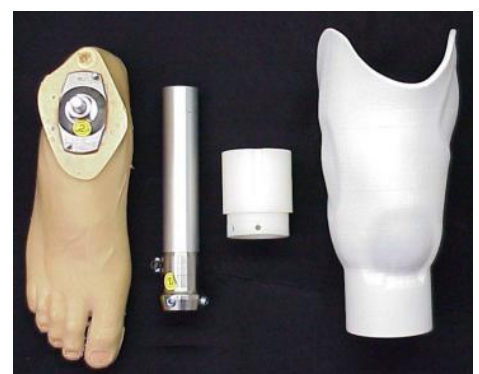

(b)

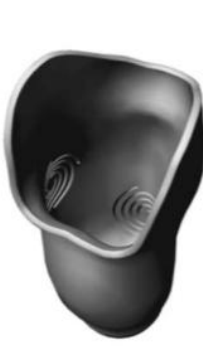

(c)

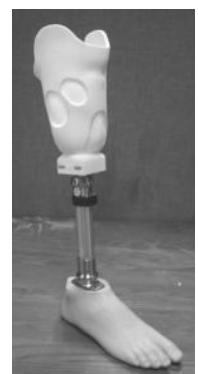

(d)

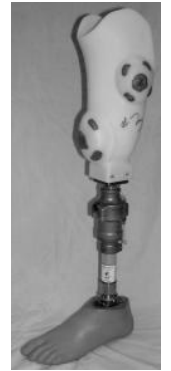

(e)

Fig. 11 AM of prosthetics by the UT group in (a) 2000 [34], (b) 2001 [35], (c) 2005 [39] (d) 2006 [42], and (e) 2008 [44].

In 2000s, a group at the National University of Singapore developed a Rapid Socket Manufacturing Machine (RSMM), which used the FDM technology to deposit PP (Fig. 12(a)) $[36,37]$. The material strengths of PP fabricated by RSMM had 12-23\% lower ultimate tensile strength when compared to that of regular PP [36]. The structural integrity of PP sockets with reinforced double-wall structure made by RSMM had good static loading strength and passed a cyclic test of 250,000 cycles with no observable failure [36]. The clinical study showed that this PP socket had comparable performance in comparison to a conventional socket. The fabrication time of a socket using RSMM was about 3.5 hours [40]. The group also fabricated prosthetic sockets using FDM and conducted clinical trials, which showed that FDM sockets had an equivalent performance in comparison to conventional sockets [38]. 


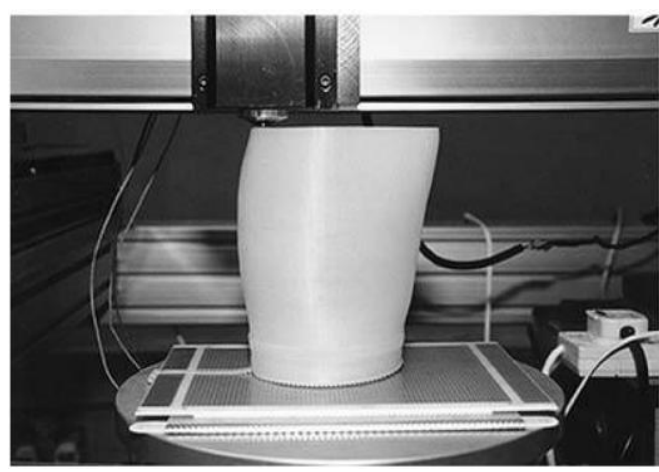

(a)

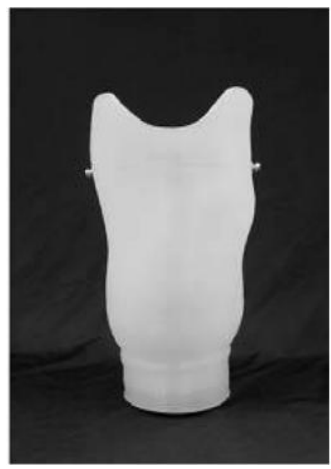

(b)

Fig. 12 The Rapid Socket Manufacturing Machine: (a) system and (b) fabricated socket [37].

Herbert et al. [41] utilized the plaster based 3D printing to fabricate prosthetic sockets and showed that good comfort can be achieved, but the strength and durability were not studied. A group at National Cheng Kung University studied coating FDM sockets with a polyester resin layer, as shown in Fig. 13, to increase the flexural strength $[45,46]$. This group also developed a system which used a vacuum forming tool to capture the geometry of the residual limb under a controlled negative pressure and AM was used to fabricate a positive mold to represent the residual limb [48]. The positive mold could be 3D scanned and used to produce the geometry of the prosthetic sockets to be additive manufactured and coated with polyester resin.

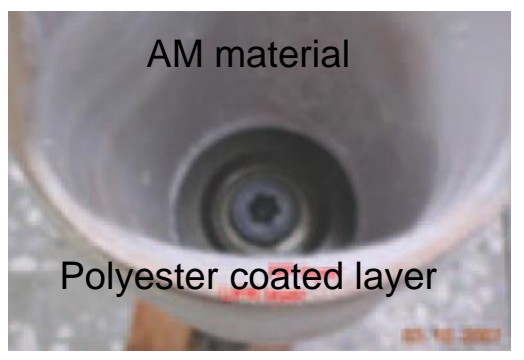

(a)

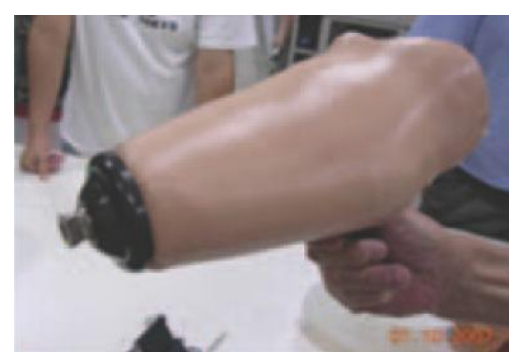

(b)

Fig. 13. Sockets infiltrated with unsaturated polyester: (a) cross sectional view and (b) assembly [46].

Recently, a group at Massachusetts Institute of Technology applied 3D-printing (PolyJet ${ }^{\circledR}$ ) to fabricate prosthetic sockets with locally variable hardness (impedance) [49]. The hardness of the socket was based on mapping the stiffness of the residual limb from reconstructed magnetic resonance images (MRI), as shown in Fig. 14(a). The socket was designed (Fig. 14(b)) such 
that its hardness had an inverse relationship to the tissue compliance at each contact point (i.e. more compliant tissue rested against harder material, and vice versa). The socket with this design (Fig. 14(c)) yielded a reduction in contact pressure of about $10-20 \%$ and a $16 \%$ faster self-selected walking speed. This group further refined the resolution of variable stiffness to a voxel-scale level through material property mapping [50]. A concept of AM for pressure sensing elements by locally varying transparency and index of refraction was also proposed.

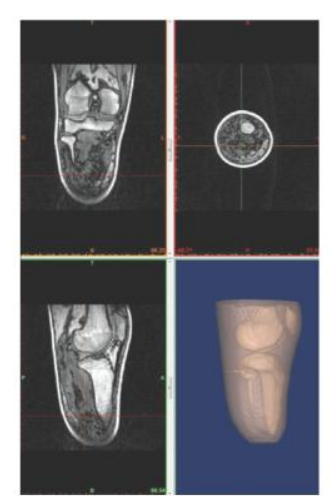

(a)

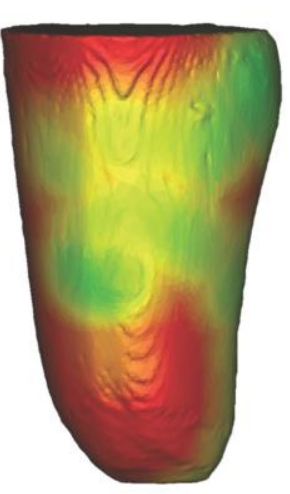

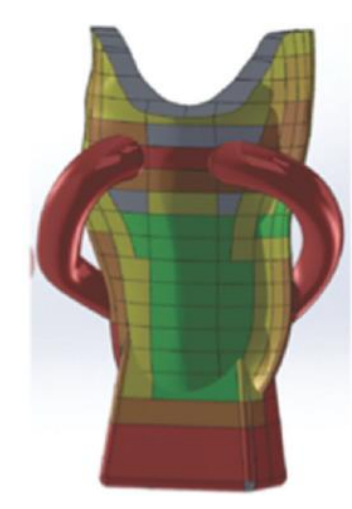

(b)

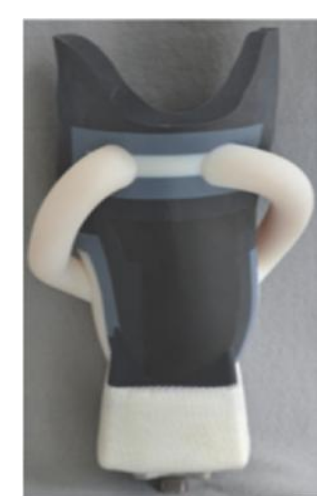

(c)

Fig 14: Socket with variable impedance to match tissue compliance: (a) map of tissue compliance from MRI, (b) 3D design, and (c) AM socket [49].

\section{Other Applications}

Besides FO, AFO, and lower-limb prosthetic sockets, AM has been used in other types of O\&P, such as custom wrist splints [51], auricular prostheses [52, 53], and prosthetic hands and feet. Paterson et al. [51] studied the processes of SLS, FDM, SLA, and 3D-printing to fabricate custom wrist splints with digital design and features that can only be made by AM (Fig. 15(a)). For prosthetic hands, Dalley et al. $[54,55]$ used AM to fabricate light-weight and high-strength yet complex components for prosthetic hand. Zuniga et al. [56] developed the "Cyborg Beast," an additive manufactured prosthetic hand for children with upper-limb differences using a distance-fitting procedure. Eleven children, ages ranging from 3 to 16 years, were fitted with this low cost prosthetic hand (Fig. 15(b)) [56]. The study showed the feasibility of its use by children in developing countries. Leddy et al. [57] used additive manufactured molds to fabricate components for prosthetic hands with multiple and composite materials to achieve light weight and high stiffness.

For prosthetic feet, South et al. [58] used SLS with Rilsan ${ }^{\mathrm{TM}}$ D80 (Nylon 11) for energy storage and return and compared the SLS and carbon fiber (CF) foot. Results showed that 
similar mechanical properties as desired from CF feet can be achieved by the SLS foot. Topology optimization was also used to minimize the material usage (Fig. 15(c)). Ventura et al. [59] used the SLS to fabricate prosthetic ankles with different stiffness levels and showed that compliant ankles with increased ankle dorsi-flexion and energy storage and return could help to reduce the residual leg's ground reaction force and asymmetric loading of both legs.

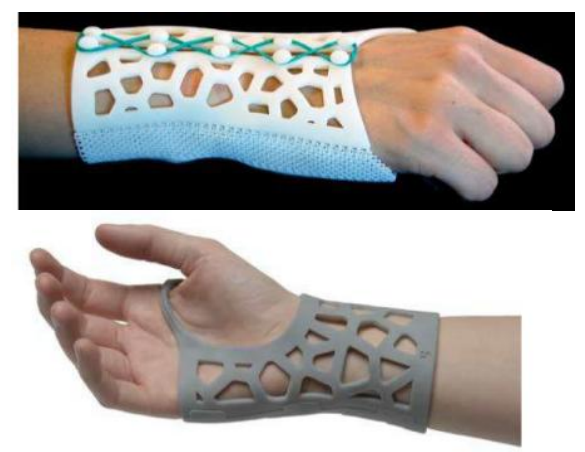

(a)

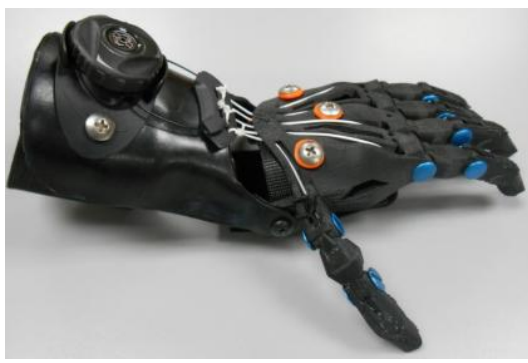

(b)

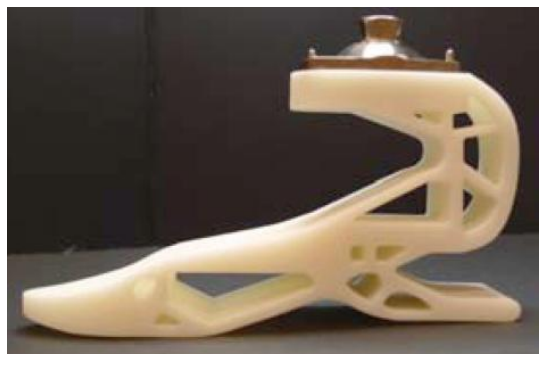

(c)

Fig. 15 Other applications of AM of orthoses and prostheses: (a) wrist splints, (b) prosthetic hand, and (c) prosthetic ankle.

\section{Trends and Future Challenges}

This paper summarized the traditional and AM processes of custom FOs, AFOs, lower limb prosthetic sockets, and other applications in the past 25 years. In limited clinical evaluations, the AM technology has demonstrated the capability of fabricating custom FOs, AFOs, and lower limb prosthetic sockets with good fit and adequate strength. However, studies clearly show that there are clinical, technological (on both design and manufacturing), and financial barriers that need to be overcome before the AM technology can be adopted for full-scale implementation in a service system for custom O\&P.

While a number of research studies have been conducted for AM of O\&P, major clinical facilities have not yet adopted AM for mass production of custom O\&P. Several barriers need to be overcome in order to enable the adoption of AM in the orthotics and prosthetics industry. These barriers include: the lack of clinical and design interface for an AM system [11, 43], uneconomic throughput and material cost [12, 15], and limited material strength [41, 46].

Clinical and design interface is a key to the adoption of AM by the society [10]. In the research setting, several software platforms were used to process the 3D geometry of an 
orthosis and a prosthetic socket. However, the current O\&P software cannot take the 3D scan data, modify the geometry of the 3D surface, convert the surface into a solid object, and create trimlines. In order to achieve these in an efficient way, a software platform that is tailored for AM of O\&P is required. Moreover, when embracing AM technologies, the design is not limited by the same shapes and features as the conventional O\&P. AM allows the design and fabrication of O\&P with increased functionality, complexity, and aestheticism without increasing manufacturing time. Through better efficacy and fit and faster delivery time (such as the sameday visit), AM has the potential to break the clinical barrier for O\&P.

Cost and fabrication time are two other key barriers to the adoption of AM of O\&P. Initial equipment investment is high for AM. As AM technologies and industry develop, it is expected that the price of $\mathrm{AM}$ equipment will go down and material deposition rate and throughput will increase. Better designs through the use of techniques such as topology optimization [11] and sparse structure [18] will ensure the material is used in efficient manner and the manufacturing time is minimized. Furthermore, a design tool that can be easily incorporated into orthotists' workflow is desired.

Safety and durability are also important for O\&P. O\&Ps are used under repeated loading and requires both ultimate strength and fatigue strength in the AM material. While most prior studies on AM of O\&P were done in the laboratory setting, a need exists for a long-term study to investigate their durability [41]. The development of carbon fiber reinforced thermoplastic material [60-62] provides the opportunity for stronger AM materials for O\&P applications. Quality control of the AM process and good manufacturing practice for O\&P also need to be closely examined.

Implementing a cyber-physical system for AM of O\&P is an ongoing trend, yet efforts are still needed to develop and integrate such a system. In such a cyber-physical system, distributed $\mathrm{AM}$ and distributed computation (for design and optimization) can best allocate and utilize resources. For example, the clinician may only need to take the $3 \mathrm{D}$ scan from the patient and prescribe the requirements for the orthoses or prosthesis. The geometry processing, design, and optimization can be done remotely in a cloud-based design center. The design of O\&P, upon the clinician's approval, can then be sent to the AM equipment in the clinic via the Internet for manufacturing. Such a cyber-manufacturing system lowers the entry requirement for clinicians and clinical facilities. Also, not all facilities have the economic scale to fully utilize the AM equipment. A distributed $\mathrm{AM}$ system with networked $\mathrm{AM}$ equipment in a region is a future trend for full implementation of AM for custom O\&P. 


\section{Acknowledgements}

The authors are thankful for the support from Blue Cross Blue Shield of Michigan Foundation (Grant 2158.II). Our research results are based upon work supported by the National Science Foundation Partnerships for Innovation: Building Innovation Capacity (PFI:BIC) subprogram under Grant No. 1534003. Any opinions, findings, and conclusions or recommendations expressed in this material are those of the author(s) and do not necessarily reflect the views of the National Science Foundation.

\section{References}

[1] D. G. Shurr and J. W. Michael, Prosthetics and orthotics, 2nd Editio. Upper Saddle River, NJ: Prentice Hall, 2001.

[2] American Orthotic \& Prosthetic Association (AOPA) Fact Sheet, 2013. http://www.aopanet.org/media/fact-sheet/

[3] G. M. Berke, J. Fergason, J. R. Milani, J. Hattingh, M. McDowell, V. Nguyen, and G. E. Reiber, "Comparison of satisfaction with current prosthetic care in veterans and servicemembers from Vietnam and OIF/OEF conflicts with major traumatic limb loss," J. Rehabil. Res. Dev., vol. 47, no. 4, pp. 361-372, 2010.

[4] R. Gailey, K. Allen, J. Castles, J. Kucharik, and M. Roeder, "Review of secondary physical conditions associated with lower-limb amputation and long-term prosthesis use," J. Rehabil. Res. Dev., vol. 45, no. 1, pp. 15-30, 2008.

[5] Centers for Medicare \& Medicaid Services, "Part B National Summary Data File." [Online]. Available: https://www.cms.gov/Research-Statistics-Data-and-Systems/DownloadablePublic-Use-Files/Part-B-National-Summary-Data-File/Overview.html. [Accessed: 04-Nov2015].

[6] J. H. P. Pallari, K. W. Dalgarno, and J. Woodburn, "Mass customisation of foot orthoses for rheumatoid arthritis," in Proceedings of the 19th Annual International Solid Freeform Fabrication Symposium, 2008, pp. 130-137.

[7] J. Saleh and K. Dalgarno, "Cost and benefit analysis of fused deposition modelling (FDM) technique and selective laser sintering (SLS) for fabrication of customised foot orthoses," in Proc. 4th Int. Conf. Adv. Res. Virtual Rapid Manuf., Innovative Dev. Des. Manuf., 2009.

[8] S.-P. Sun, Y.-J. Chou, and C.-C. Sue, "Classification and mass production technique for three-quarter shoe insoles using non-weight-bearing plantar shapes," Appl. Ergon., vol. 40, no. 4, pp. 630-635, 2009.

[9] D. Cook, V. Gervasi, R. Rizza, S. Kamara, and X.-C. Liu, "Additive fabrication of custom pedorthoses for clubfoot correction," Rapid Prototyp. J., vol. 16, no. 3, pp. 189-193, 2010.

[10] J. H. P. Pallari, K. W. Dalgarno, and J. Woodburn, "Mass customization of foot orthoses 
for rheumatoid arthritis using selective laser sintering," IEEE Trans. Biomed. Eng., vol. 57, no. 7, pp. 1750-1756, Jul. 2010.

[11] J. H. P. Pallari, K. W. Dalgarno, J. Munguia, L. Muraru, L. Peeraer, S. Telfer, and J. Woodburn, "Design and additive fabrication of foot and ankle-foot orthoses," in Proceedings of the 21st Annual International Solid Freeform Fabrication Symposium, 2010, pp. 834-845.

[12] A. S. Salles and D. E. Gyi, "Delivering personalised insoles to the high street using additive manufacturing," Int. J. Comput. Integr. Manuf., no. April 2013, pp. 1-15, Aug. 2012.

[13] A. S. Salles and D. E. Gyi, "The specification of personalised insoles using additive manufacturing," Work, vol. 41, pp. 1771-1774, 2012.

[14] A. S. Salles and D. E. Gyi, "An evaluation of personalised insoles developed using additive manufacturing," J. Sports Sci., vol. 31, no. 4, pp. 442-450, 2013.

[15] J. M. Saleh, "Cost modelling of rapid manufacturing based mass customisation system for fabrication of custom foor orthoses," University of Newcastle, 2013.

[16] C. E. Dombroski, M. E. Balsdon, and A. Froats, "The use of a low cost 3D scanning and printing tool in the manufacture of custom-made foot orthoses: a preliminary study.," $B M C$ Res. Notes, vol. 7, no. 1, p. 443, 2014.

[17] S. Telfer, J. Pallari, J. Munguia, K. Dalgarno, M. McGeough, and J. Woodburn, "Embracing additive manufacture: implications for foot and ankle orthosis design," BMC Musculoskelet Disord, vol. 13, p. 84, 2012.

[18] R. K. Chen, L. Chen, J. Wensman, and A. A. J. Shih, "Rapid fabrication of custom orthoses with sparse structure and topology optimization using additive manufacturing," in RAPID, 2014.

[19] S. Milusheva, D. Tochev, L. Stefanova, and Y. Toshev, "Virtual models and prototype of individual ankle foot orthosis," in Proceedings of ISB XXth Congress - ASB 29th Annual Meeting, 2005, p. 227.

[20] S. M. Milusheva, E. Y. Tosheva, Y. E. Toshev, and R. Taiar, "Ankle foot orthosis with exchangeable elastic elements," Ser. Biomech., vol. 23, no. 1, pp. 90-95, 2007.

[21] M. C. Faustini, R. R. Neptune, R. H. Crawford, and S. J. Stanhope, "Manufacture of passive dynamic ankle-foot orthoses using selective laser sintering," IEEE Trans. Biomed. Eng., vol. 55, no. 2, pp. 784-790, Feb. 2008.

[22] C. Mavroidis, R. G. Ranky, M. L. Sivak, B. L. Patritti, J. DiPisa, A. Caddle, K. Gilhooly, L. Govoni, S. Sivak, M. Lancia, R. Drillio, and P. Bonato, "Patient specific ankle-foot orthoses using rapid prototyping," J. Neuroeng. Rehabil., vol. 8, no. 1, pp. 1-11, Jan. 2011.

[23] E. S. Schrank and S. J. Stanhope, "Dimensional accuracy of ankle-foot orthoses constructed by rapid customization and manufacturing framework," J. Rehabil. Res. Dev., vol. 48, no. 1, pp. 31-42, 2011. 
[24] V. Creylman, L. Muraru, J. Pallari, H. Vertommen, and L. Peeraer, "Gait assessment during the initial fitting of customized selective laser sintering ankle foot orthoses in subjects with drop foot," Prosthetics Orthcubtics Int., vol. 37, no. 2, pp. 132-138, 2013.

[25] E. S. Schrank, L. Hitch, K. Wallace, R. Moore, and S. J. Stanhope, "Assessment of a virtual functional prototyping process for the rapid manufacture of passive-dynamic anklefoot orthoses.," J. Biomech. Eng., vol. 135, no. 10, pp. 101011-7, Oct. 2013.

[26] R. Chen, L. Chen, B. Tai, Y. Wang, A. Shih, and J. Wensman, "Additive manufacturing of personalized ankle-foot orthosis," in Proceedings of NAMRI/SME, 2014.

[27] N. G. Harper, E. M. Russell, J. M. Wilken, and R. R. Neptune, "Selective laser sintered versus carbon fiber passive-dynamic ankle-foot orthoses: a comparison of patient walking performance.," J. Biomech. Eng., vol. 136, no. 9, p. 091001, Sep. 2014.

[28] W. E. Rogers, R. H. Crawford, J. J. Beaman, and N. E. Walsh, "Fabrication of prosthetic sockets by selective laser sintering," in Solid Freeform Fabrication Symposium Proceedings, 1991, no. 6, pp. 158-163.

[29] W. E. Rogers, R. H. Crawford, V. Faulkner, and J. J. Beaman, "Fabrication of an integrated prosthetic socket using solid freeform fabrication," in 7th World Congress of the International Society for Prosthetics and Orthotics, 1992, p. b12.

[30] J. S. Rovick, R. B. Chan, R. L. Van Vorhis, and D. S. Childress, "Computer-aided manufacturing in prosthetics: various possibilities using industrial equipment," in 7th World Congress of the International Society for Prosthetics and Orthotics, 1992.

[31] J. S. Rovick, "An additive fabrication technique for the computer-aided manufacturing of sockets," in 7th World Congress of the International Society for Prosthetics and Orthotics, 1992, p. b13.

[32] D. Freeman and L. Wontorcik, "Stereolithography and prosthetic test socket manufacture: a cost/benefit analysis," J. Prosthetics Orthot., vol. 10, no. 1, pp. 17-20, 1998.

[33] B. Rogers, S. Stephens, A. Gitter, G. Bosker, and R. Crawford, "Double-wall, transtibial prosthetic socket fabricated using selective laser sintering: a case study," J. Prosthetics Orthot., vol. 12, no. 3, pp. 97-103, 2000.

[34] S. Stephens, R. Crawford, W. Rogers, A. Gitter, and G. Bosker, "Manufacture of compliant prosthesis sockets using selective laser sintering," in 11th Freeform Fabrication Symposium, 2000, pp. 565-577.

[35] B. Rogers, A. Gitter, G. Bosker, M. Faustini, M. Lokhande, and R. Crawford, "Clinical evaluation of prosthetic sockets manufactured by selective laser sintering," in 2001 Solid Freeform Fabrication Symposium Proceedings, 2001, pp. 505-512.

[36] J. C. H. Goh, P. V. S. Lee, and P. Ng, "Structural integrity of polypropylene prosthetic sockets manufactured using the polymer deposition technique.," Proc. Inst. Mech. Eng. H., vol. 216, no. 6, pp. 359-68, 2002.

[37] P. Ng, P. S. V. Lee, and J. C. H. Goh, "Prosthetic sockets fabrication using rapid prototyping technology," Rapid Prototyp. J., vol. 8, no. 1, pp. 53-59, 2002. 
[38] F. E. H. Tay, M. a. Manna, and L. X. Liu, "A CASD/CASM method for prosthetic socket fabrication using the FDM technology," Rapid Prototyp. J., vol. 8, no. 4, pp. 258-262, 2002.

[39] M. C. Faustini, R. H. Crawford, R. R. Neptune, W. E. Rogers, and G. Bosker, "Design and Analysis of Orthogonally Compliant Features for Local Contact Pressure Relief in Transtibial Prostheses," J. Biomech. Eng., vol. 127, no. 6, p. 946, 2005.

[40] J. Y. H. Fuh, W. Feng, and W. S. Wong, "Modelling, Analysis and Fabrication of Belowknee Prosthetic Sockets Using Rapid Prototyping," in Advanced Manufacturing Technology for Medical Applications: Reverse Engineering, Software Conversion and Rapid Prototying, I. Gibson, Ed. John Wiley \& Sons, Ltd., 2005, pp. 207-226.

[41] N. Herbert, D. Simpson, W. D. Spence, and W. Ion, "A preliminary investigation into the development of 3D printing of prosthetic sockets," J. Rehabil. Res. Dev., vol. 42, no. 2, pp. 141-146, 2005.

[42] M. C. Faustini, R. R. Neptune, R. H. Crawford, W. E. Rogers, and G. Bosker, "An experimental and theoretical framework for manufacturing prosthetic sockets for transtibial amputees.," IEEE Trans. Neural Syst. Rehabil. Eng., vol. 14, no. 3, pp. 304-10, Sep. 2006.

[43] B. Rogers, G. W. Bosker, R. H. Crawford, M. C. Faustini, R. R. Neptune, G. Walden, and A. J. Gitter, "Advanced trans-tibial socket fabrication using selective laser sintering.," Prosthetics Orthcubtics Int., vol. 31, no. 1, pp. 88-100, Mar. 2007.

[44] B. Rogers, G. Bosker, M. Faustini, G. Walden, R. R. Neptune, and R. Crawford, "Case report: variably compliant transtibial prosthetic socket fabricated using solid freeform fabrication," J. Prosthetics Orthot., vol. 20, no. 1, pp. 1-7, 2008.

[45] L. H. Hsu, G. F. Huang, C. T. Lu, C. W. Lai, Y. M. Chen, I. C. Yu, and H. S. Shih, "The Application of Rapid Prototyping for the Design and Manufacturing of Transtibial Prosthetic Socket," Mater. Sci. Forum, vol. 594, pp. 273-280, 2008.

[46] L. H. Hsu, G. F. Huang, C. T. Lu, D. Y. Hong, and S. H. Liu, "The development of a rapid prototyping prosthetic socket coated with a resin layer for transtibial amputees," Prosthet. Orthot. Int., vol. 34, no. 1, pp. 37-45, 2010.

[47] J. T. Montgomery, M. R. Vaughan, and R. H. Crawford, "Design of an actively actuated prosthetic socket," Rapid Prototyp. J., vol. 16, no. 3, pp. 194-201, 2010.

[48] W.-C. Chuang, H.-H. Hsieh, L.-H. Hsu, H.-J. Ho, J.-T. Chen, and M.-J. Tzeng, "A System for Supporting the Design of Total Surface Bearing Transtibial Sockets," Comput. Aided. Des. Appl., vol. 8, no. 5, pp. 723-734, 2011.

[49] D. M. Sengeh and H. Herr, "A variable-impedance prosthetic aocket for a transtibial amputee designed from magnetic resonance imaging data," J. Prosthetics Orthot., vol. 25, no. 3, pp. 129-137, 2013.

[50] E. L. Doubrovski, E. Y. Tsai, D. Dikovsky, J. M. P. Geraedts, H. Herr, and N. Oxman, "Voxel-based fabrication through material property mapping: A design method for bitmap 
printing," Comput. Des., vol. 60, pp. 3-13, 2014.

[51] A. M. Paterson, R. Bibb, R. I. Campbell, and G. Bingham, "Comparing additive manufacturing technologies for customised wrist splints," Rapid Prototyp. J., vol. 21, no. 3, pp. 230-243, 2015.

[52] K. Subburaj, C. Nair, S. Rajesh, S. M. Meshram, and B. Ravi, "Rapid development of auricular prosthesis using CAD and rapid prototyping technologies," Int. J. Oral Maxillofac. Surg., vol. 36, no. 10, pp. 938-943, 2007.

[53] P. Liacouras, J. Garnes, N. Roman, A. Petrich, and G. T. Grant, "Designing and manufacturing an auricular prosthesis using computed tomography, 3-dimensional photographic imaging, and additive manufacturing: a clinical report," $J$ Prosthet Dent, vol. 105, no. 2, pp. 78-82, 2011.

[54] S. A. Dalley, T. E. Wiste, T. J. Withrow, and M. Goldfarb, "Design of a multifunctional anthropomorphic prosthetic hand with extrinsic actuation," IEEE/ASME Trans.

Mechatronics, vol. 14, no. 6, pp. 699-706, 2009.

[55] S. A. Dalley, T. E. Wiste, H. A. Varol, and M. Goldfarb, "A multigrasp hand prosthesis for transradial amputees," in 2010 Annual International Conference of the IEEE Engineering in Medicine and Biology Society, 2010, pp. 5062-5065.

[56] J. Zuniga, D. Katsavelis, J. Peck, J. Stollberg, M. Petrykowski, A. Carson, and C. Fernandez, "Cyborg beast: a low-cost 3d-printed prosthetic hand for children with upperlimb differences," BMC Res. Notes, vol. 8, no. 10, 2015.

[57] M. T. Leddy, J. T. Belter, K. D. Gemmell, and A. M. Dollar, "Lightweight custom composite prosthetic components using an additive manufacturing - based molding technique," pp. 2-7.

[58] B. J. South, N. P. Fey, G. Bosker, and R. R. Neptune, "Manufacture of energy storage and return prosthetic feet using selective laser sintering.," J. Biomech. Eng., vol. 132, no. 1, pp. 015001-1-6, Jan. 2010.

[59] J. D. Ventura, G. K. Klute, and R. R. Neptune, "The effects of prosthetic ankle dorsiflexion and energy return on below-knee amputee leg loading," Clin. Biomech., vol. 26, no. 3, pp. 298-303, 2011.

[60] R. W. G. Iv, D. G. Baird, and J. H. Bøhn, "Effects of processing conditions on short TLCP fiber reinforced FDM parts," Rapid Prototyp. J., vol. 4, no. 1, pp. 14-25, 1998.

[61] W. Zhong, F. Li, Z. Zhang, L. Song, and Z. Li, "Short fiber reinforced composites for fused deposition modeling," Mater. Sci. Eng. A, vol. 301, no. 2, pp. 125-130, 2001.

[62] S. Christ, M. Schnabel, E. Vorndran, J. Groll, and U. Gbureck, "Fiber reinforcement during 3D printing," Mater. Lett., vol. 139, pp. 165-168, 2015. 